\title{
School Principals and Teachers' Perceptions of Inclusive Education in Sebeta Town Primary Government Schools, Sebeta, Ethiopia
}

\author{
Alemayehu Dugassa Geleta \\ Sebeta Special Needs Education Teachers College, Ethiopia
}

\begin{abstract}
The main purpose of this study was to explore the perceptions of school principals and teachers of Sebeta town primary government schools (grade 1-8) on inclusive education. To achieve this purpose a descriptive survey research designs was implemented. The data were collected from 16 school principals and 78 teachers of eight different schools using questionnaire, structured interview and observational check list. Quantitative data were analyzed using SPSS version 20.The finding of the study revealed that, school principals and teachers have positive perceptions towards inclusive education. However, due to the lack of inclusive educational materials and unsuitable school physical structures, the level of implementation of inclusive education in general schools were very poor (mean score $<9)$. There was no significant difference $(p>$ 0.05 ) between teachers of different schools, gender, teaching experience, education level, and subject of graduation of teachers' on perceptions of inclusive education. Support given to schools from various educational stakeholders to implement inclusive education is unsatisfactory. Thus, collaborative efforts between schools and various educational stakeholders to implement inclusive education in general schools are recommended.
\end{abstract}

\section{Introduction}

Inclusive education is a wide range of strategies, activities and processes that seek to make a reality of the universal right to quality, relevant and appropriate education [1]. It is a critical component in the development of the whole child. Inclusion promotes quality and equity education for all without any type of barrier or exclusion including those who may be potentially marginalized due to disability, gender, emotional or behavioral problems, family background, ethnicity, giftedness, migrants, poverty, hearing or visual impairment, language delay, among others [2]. Inclusion in education is recognized as a basic human right and the foundation for a more just and equal society [3].
Education for all identified inclusive education as one of the key strategies to address issues of marginalization and exclusion [4]. However, various factors could hinder the implementation of inclusive education in general schools. Andrews and Frankel [5] found that lack of appropriate infrastructure and nonexistence of adapted curriculum was factors affected the experiences of teachers and their attitudes towards inclusion. Kenyan study indicated that the degree of administrative support and vision is the most powerful predictor of the general teacher's attitude towards full inclusion [6].

For inclusive education to succeed, it is vitally important that teachers, school principals and other education stakeholders maintain a positive attitude towards inclusion. Collaboration between teachers of different educational background and teaching experience are very important to solve emerging problems in the school atmosphere. Literature has shown that the success of the inclusive education depends to a large extent on the willingness and the ability of teachers to make accommodations for individuals with special needs [7]. Numerous studies found that teachers agree that the inclusive education is important, but many find it difficult to apply. The roles of teacher training colleges are very important in this aspect to build teachers confidence. Exposure to observing teaching children with special needs in inclusive setting is one of the essential components in the process of breaking down barriers and building positive attitude [8].

Currently, the government of Ethiopia has been implementing measures to improve participation of special needs learners in schools. In Ethiopia, primary education lasts 8 years and is split into grades 1-4 (primary first cycle) and grades 5-8 (primary second cycle). Hence, this study concentrated on grades $1-8$ primary education. Since the government prepared the national Education and Training Policy (ETP) in 1994 the education system expanded. Despite government policy of inclusive education, children with special needs remain amongst the most disadvantaged children in Ethiopia [9]. 
Thus, the current study set out to explore the perceptions of schools principals and teachers on inclusive education, and to find some possible factors that could hinder implementation of inclusive education in Sebeta general primary government schools. Sebeta town is located in Oromia national regional state, Oromia special zone surrounding Finfine at a distance of $24 \mathrm{~km}$ from the capital city of Ethiopia, Addis Ababa. In Sebeta there are eight (8) general primary government schools, one (1) special blind school and one (1) special needs education teacher's College. Conducting a research on inclusive education practices is essential and timely issue in order to identify its challenges and forward alternative solution for better practices as well as to improve its valuable contribution for students' learning in the primary general schools.

\section{Statement of the problems}

There are some children who are marginalized due to disability, emotional and behavioral problems, hearing or visual impairments, among others [2]. Unsuitable school environment, lack of infrastructure, lack of appropriate educational materials, and perceptions of various educational stakeholders towards disability could be some of factors affected implementation of inclusive education in general schools. However, without inclusion it is impossible to achieve equity education for all. In order to fill this gap, it is very important to conduct a research on school principals and teachers' perceptions of inclusive education in Sebeta town primary government schools. Therefore, this study attempted to address the following basic questions:

- What is the knowledge and perceptions of schools principals and teachers towards inclusive education?

- Is there any significance difference between teachers of different schools on ways of implementation of inclusive education?

- How do school principals and teachers perceive staff development and collaboration in creation of inclusive school environment?

\section{Methodology}

\subsection{Research Design}

Descriptive survey research designs were implemented to obtain relevant and precise information concerning the current phenomena of inclusive education at primary government schools (Grades 1-8) of Sebeta town. This design were helpful to collect information, gather opinions and record attitudes from school principals and teachers regarding the use of selected teaching/learning resources available in relation to the implementation of inclusive education for special needs learners [10]. The approach of the study was more of quantitative than qualitative as the ultimate concern was to establishing specific relationship among the components [11]. The study was carried out in eight primary government schools (Grades $1-8$ ) at Sebeta town. The schools selected for these study were Abdi biya, Alam gana, Dalati, Dima guranda, Dima magno, Karabu, Mulugeta Gadile, and Roge and gamme primary schools. They were selected for participation not only for the accessibility, availability, and familiarity to the researcher, but also because they have more chance to get continuous training on inclusive education from Sebeta Special Needs Education Teachers Education College than neighboring rural primary government schools. The study was conducted within the period of January, 2015 - September, 2015.

\subsection{Sample Selection}

The target population for the study was school principals, deputy principals and teachers of government primary schools found at Sebeta town. In this study deputy principals considered as principals for the purpose of data analysis. There are eight general government primary schools in Sebeta town. Each school had one principal and one deputy principal. All principals and deputy principals were purposively sampled since they have better insight about the inclusive education practices in the schools. On the other hand, ten (10) teachers were randomly selected from each school except from Abdi biya primary school eight (8) teachers were selected. Thus, a total of 94 respondents were participated in this study.

\subsection{Data collection instruments and procedure}

Questionnaires, semi-structured interview and observation checklist were used as the data collection instruments in this study. Questionnaires are written forms that ask exact questions of all individuals in the sample group, and which respondents can answer at their own convenience [12]. Both open-ended and closed-ended questions were included in the questionnaire to create an opportunity for respondents to express their feeling freely. The questionnaire were used in part one to generate data on the background of school principals and teachers. 
Part two were filled by respondents on statements relating to administrative support and actual practice in the implementation of inclusive education in classrooms, where rating was made indicating the respondents' perceptions of how the school administration support implementation of inclusive education. In addition, teachers and school principals' attitudes towards implementations of inclusive education in class room and factors contributed to their attitude were filled by respondents. Farther, the participants were indicated their opinion based on level of their agreement on actual practice of inclusive education in the school. An observation checklist was conducted by researcher in each school to determine the availability of inclusive education material, physical structures of the school, accessibility of classrooms fields and toilets. In addition, face to face semi-structured interview was held with school principals and special needs education teachers. This was used for qualitative and in-depth explanation of the results of the questionnaires. The interview focused on the school principals' support in implementing inclusive education values, improving school environment in terms of availing materials and physical structures to accommodate special needs learners especially those with physical impairments, the school administration providing support on staff collaboration and development in inclusive education practice.

\section{Data Analysis}

In this study both quantitative and qualitative methods of data analysis were utilized. The quantitative data were organized, tabulated and analyzed by using SPSS version 20. In addition to this, qualitative data were analyzed by using narration in the way it supplements the quantitative analysis. Frequency analysis was conducted to identify valid response percentages for all questions in the survey. Furthermore, one-way ANOVA were used to analyze any significance difference among teachers and between school principals and teachers' perceptions towards inclusive education at $95 \%$ confidence interval $(\mathrm{P}<0.05)$.

\subsection{Results}

A total of 94 questionnaires were distributed to the school principals and teachers. Out of these, $100 \%$ of the questionnaires were returned after filled by respondents. It mainly focuses on characteristics of respondents, perceptions and knowledge of school principals and teachers towards inclusive education, factors hindering implementation of inclusive education and support provided to teachers from different stakeholders to implement inclusive education.

\subsection{Demographic characteristics of the respondents}

In this study Sebeta primary government schools' principals and teachers were the respondents. Personal information was collected through questionnaire which includes gender, teaching experiences, educational level and subject in which they were graduated. This information presented as follows in the Table 1 .

As Table 1 indicates, the number of male respondents $48(51.06 \%)$ and female respondents 46 (48.94\%) participated in this study were nearly similar. Most school principals and teachers 42 (44.68\%) had a teaching experiences between 1 - 5 years where as $16(17.02 \%), 12(12.77 \%), 11(11.70)$, 9 (9.57) and $4(4.26 \%)$ of them had a teaching experiences between $6-10$ years, $11-15$ years, 21 - 25 years, $16-20$ years and greater than 25 years respectively. Similarly, the education level of most of respondents 66 (70.21\%) were Diploma. Most of them were graduates of languages $33(35.11 \%)$ and natural sciences $33(35.11 \%$ ) (see Table 1$)$.

\subsection{School principals and teachers' knowledge and perceptions of inclusive education}

Respondents were given self-rated questionnaire to identify their knowledge and perceptions towards inclusive education. They indicated their level of agreements on seven different variables. The item responses of the 94 respondents were aggregated and scored by summing the responses of participants on these seven variables to yield scale scores. The results were analyzed using independent t-test as indicated in Table 2. It was assumed that the mean values less than 24 were related to insufficient knowledge of inclusive education. On other hand, mean values greater than or equal to 24 were related to satisfactory knowledge of inclusive education. As indicated in Table 2 above, the mean score of knowledge and perceptions of school principals and teachers were greater than 24 . This shows that both school principals and teachers have satisfactory knowledge of inclusive education. Thus, both school principals and teachers had positive attitudes towards implementation of inclusive education. However, there was significance difference between principals and teachers' knowledge and perceptions on inclusive education $(\mathrm{p}<0.05)$ (see Table 2$)$. 
Table 1. Characteristics of respondents

\begin{tabular}{|c|c|c|c|c|c|c|}
\hline \multirow{3}{*}{ Characteristics } & \multicolumn{6}{|c|}{ Respondents } \\
\hline & \multicolumn{2}{|c|}{$\begin{array}{l}\text { Teachers } \\
(N=78)\end{array}$} & \multicolumn{2}{|c|}{$\begin{array}{l}\text { Principals }(N= \\
\text { 16) }\end{array}$} & \multicolumn{2}{|c|}{ Total $(N=94)$} \\
\hline & № & $\%$ & № & $\%$ & № & $\%$ \\
\hline \multicolumn{7}{|l|}{ Gender } \\
\hline Male & 34 & 43.6 & 14 & 87.5 & 48 & 51.06 \\
\hline Female & 44 & 56.4 & 2 & 12.5 & 46 & 48.94 \\
\hline \multicolumn{7}{|c|}{ Teaching experiences in year } \\
\hline $1-5$ & 36 & 46.2 & 6 & 37.5 & 42 & 44.68 \\
\hline $6-10$ & 13 & 16.7 & 3 & 18.8 & 16 & 17.02 \\
\hline $11-15$ & 8 & 10.3 & 4 & 25 & 12 & 12.77 \\
\hline \multicolumn{7}{|l|}{ Education level } \\
\hline Certificate & 5 & 6.4 & - & - & 5 & 5.32 \\
\hline Diploma & 57 & 73.1 & 9 & 56.2 & 66 & 70.21 \\
\hline First Degree & 16 & 20.5 & 7 & 43.8 & 23 & 24.47 \\
\hline \multicolumn{7}{|l|}{ Subject of graduation } \\
\hline Languages & 28 & 35.89 & 5 & 31.3 & 33 & 35.11 \\
\hline Social Science & 15 & 19.2 & 4 & 25.0 & 19 & 20.21 \\
\hline Natural Science & 30 & 38.5 & 3 & 18.8 & 33 & 35.11 \\
\hline SNE & 3 & 3.8 & - & - & 3 & 3.19 \\
\hline Esthetics & 2 & 2.6 & - & - & 2 & 2.13 \\
\hline Educational management & - & - & 4 & 25 & 4 & 4.26 \\
\hline
\end{tabular}

Table 2. School principals and teacher's knowledge and perceptions of inclusive education

\begin{tabular}{llllll}
\hline Characteristics & Respondents job & Mean \pm SD & \% CV & T- value & Sig (p- value) \\
\hline $\begin{array}{l}\text { Knowledge and } \\
\text { perceptions }\end{array}$ & Teacher & $24.89 \pm 4.8$ & 19.28 & & \\
\hline
\end{tabular}

Significant at $\alpha=0.05$, SD: Standard deviation, CV: Coefficient of variation

Table 3. Principals and teachers' perceptions on current levels of implementation of inclusive education in the schools

\begin{tabular}{llllll}
\hline Characteristics & Respondents job & Mean \pm SD & \% CV & T- value & Sig (p- value) \\
\hline Implementation of & Teacher & $7.19 \pm 2.44$ & 33.94 & \multirow{2}{*}{0.864} & \multirow{2}{*}{0.196} \\
inclusive education & Principals & $7.75 \pm 1.8$ & 23.23 & \\
\hline
\end{tabular}

Significant at $\alpha=0.05$, SD: Standard deviation, CV: Coefficient of variation

\subsection{Principals and teachers' perceptions towards the level of implementation of inclusive education}

Three various items were seated for respondents to indicate the current level of implementation of inclusive education in their respective schools. The responses were aggregated to yield scale scores.
Independent t-test was conducted to analyze the mean score and if there is significant variation between principals and teachers' perceptions on level of inclusive education implementation in general schools. Mean score less than 9 assumed as level of inclusive education implementation is very poor. Mean score greater than or equal to 9 assumed as 
level of implementation of inclusive education is satisfactory.

As indicated in Table 3 above, the mean score of implementations of inclusive education in general schools were very poor (mean score $<9$ ). There was no significance difference $(\mathrm{p}=0.196)$ between the perceptions of principals and teachers on level of implementation of inclusive education.

To realize the actual implementations of inclusive education, teacher commented that, "teachers need to be trained about different disabilities". Further, they would need to be trained on how to develop strategies for their students. "If teachers have not been adequately trained, then they will not feel confident enough to teach all students". One teacher said, "The need for periodic training, workshops, and seminars could be used to relay information to teachers on inclusive education." Another teacher replied, "Policy makers will have to make certain that proper tools are in place for the success of inclusive education." On other hand, class sizes would have to be reduced to allow the teacher sufficient time to accommodate all the students. The review of the curriculum to incorporate the special needs students will positively impacts the implementation of inclusive education because it will require teachers to prepare lessons that will meet the needs of all students.

\subsection{Comparison of school principals and teachers' knowledge, attitudes and level of implementation of inclusive education based on schools}

In order to identify teachers' knowledge to what extent they could implement inclusive education in general schools, they were rated on knowledge of how to implement inclusive education to support students with special needs, knowledge on ways of implementing inclusive education in the class room and levels of supporting students with special needs in the class room.

Seven knowledge item responses of the 94 participants were aggregated and scored by summing the relevant items to yield scale scores. The mean score scale were formulated differently for knowledge, attitudes and level of implementation of inclusive education. For knowledge items in analyzing the results it was assumed that the mean values greater or equal to 31.6 , between $24.6-31.5$, $17.6-24.5,10.6-17.5$ and $7-10.5$ were respectively taken as excellent, very good, good, fair and not fair.

Similarly, six attitude items were given to principals and teachers of different schools to indicate their attitudes to various factors affecting implementation of inclusive education in their schools. It was assumed that mean score greater than 24 , between $15.1-24,12.1-15,9.1-12$ and $6-9$ were respectively taken as strongly agree, agree, undecided, disagree and strongly disagree. On the other hand, three items were prepared to principals and teachers of various schools to show their opinion on the current level of implementation of inclusive education in their respective schools. It was assumed that the mean score greater or equal to 9 were taken as fair (satisfactory) implementation of inclusive education and mean score less than 9 were taken as unsatisfactory.

Accordingly, principals and teachers' levels of agreement on knowledge of inclusive education in their respective schools were varied. The knowledge mean score of principals and teachers of Dima guranda $($ mean $=29.33)$ and Mulugeta Gadilee (mean $=26.60)$ primary schools are higher than other schools (see Table 4).

On the other hand, principals and teachers attitude mean score were between $17-21$ values in implementation of inclusive education. These showed that, they agree on factors that could affect the implementations of inclusive educations (see Table 4). The current level of implementation of inclusive education in different schools showed that, the presence of significance difference among Mulugeta gadile and Dima guranda primary schools. Mulugeta Gadile primary school (mean $=8.20$ ) have higher implementation mean score than Dima guranda primary schools $($ mean $=5.66$ ). Similarly, post hoc result showed that there was significance difference $(p<0.05)$ among various schools on current level of implementation of inclusive education (see Table 4).

\subsection{Support of stakeholders to implement inclusive education in general schools}

School principals and teachers were evaluated support given by various educational stakeholders to general schools for implementation of inclusive education. They were shown level of stakeholder's support by saying; excellent, very good, good, fair and not fair as indicated in Table 5.

As the evaluation of most $28(29.79 \%)$ teachers and school principals showed the efforts made by special teachers to implement inclusive education were not fair (see Table 5). In current study the researcher were found that $30 \quad(31.91 \%)$ of respondents evaluated the level of support given by Sebeta special needs education teachers education College were very good. 
Table 4.Teachers' agreements on knowledge, attitudes and level of implementing inclusive education in various schools

\begin{tabular}{|c|c|c|c|c|c|c|}
\hline Principals and teachers & Schools & $\mathbf{N}$ & Mean \pm SD & $\begin{array}{l}\text { \% } \\
\mathrm{CV}\end{array}$ & $\mathbf{F}$ & Sig (p- value) \\
\hline \multirow{8}{*}{ Knowledge } & Abdi biya ${ }^{b^{*}}$ & 10 & $23.90 \pm 4.38$ & 18.33 & \multirow{8}{*}{2.435} & \multirow{8}{*}{0.025} \\
\hline & Karabu $^{\mathbf{b}^{*}}$ & 10 & $22.70 \pm 4.11$ & 18.11 & & \\
\hline & Dima Guranda $\mathrm{a}^{\mathrm{a}^{*}}$ & 12 & $29.33 \pm 2.57$ & 8.76 & & \\
\hline & Dalati $^{\mathbf{b}^{*}}$ & 12 & $25.16 \pm 4.85$ & 19.28 & & \\
\hline & Dima Magno b* $^{*}$ & 12 & $25.08 \pm 5.55$ & 22.13 & & \\
\hline & Mulugeta $^{\mathrm{e}^{*}}$ & 15 & $26.60 \pm 4.03$ & 15.15 & & \\
\hline & Alam Gana $\mathrm{b}^{\mathrm{b}^{*}}$ & 12 & $25.41 \pm 4.98$ & 19.60 & & \\
\hline & Roge and Gamme $\mathbf{b}^{\mathbf{b}^{*}}$ & 11 & $24.00 \pm 3.84$ & 16.00 & & \\
\hline \multirow{8}{*}{ Attitudes } & Abdi biya & 10 & $21.60 \pm 2.95$ & 13.66 & \multirow{8}{*}{1.789} & \multirow{8}{*}{0.100} \\
\hline & Karabu & 10 & $19.80 \pm 4.87$ & 24.60 & & \\
\hline & Dima Guranda & 12 & $18.25 \pm 3.38$ & 18.52 & & \\
\hline & Dalati & 12 & $19.58 \pm 4.98$ & 25.43 & & \\
\hline & Dima Magno & 12 & $20.83 \pm 3.01$ & 14.45 & & \\
\hline & Mulugeta & 15 & $19.13 \pm 5.30$ & 27.71 & & \\
\hline & Alam Gana & 12 & $17.16 \pm 5.32$ & 31.00 & & \\
\hline & Roge and Gamme & 11 & $16.00 \pm 5.67$ & 35.44 & & \\
\hline \multirow{8}{*}{$\begin{array}{l}\text { Implementation of } \\
\text { inclusive education }\end{array}$} & Abdibiya & 10 & $9.10 \pm 1.96$ & 21.54 & \multirow{8}{*}{3.613} & \multirow{8}{*}{0.002} \\
\hline & Karabu & 10 & $8.30 \pm 2.35$ & 28.31 & & \\
\hline & Dima Guranda $^{\mathbf{S}^{*}}$ & 12 & $5.66 \pm 2.05$ & 36.22 & & \\
\hline & Dalati & 12 & $5.83 \pm 1.74$ & 29.85 & & \\
\hline & Dima Magno & 12 & $7.50 \pm 1.67$ & 22.27 & & \\
\hline & Mulugeta $\mathrm{D}^{\mathrm{D}^{*}}$ & 15 & $8.20 \pm 2.56$ & 31.22 & & \\
\hline & Alam Gana & 12 & $6.75 \pm 2.56$ & 37.93 & & \\
\hline & Roge and Gamme & 11 & $7.18 \pm 1.88$ & 26.18 & & \\
\hline
\end{tabular}

Significant at $\alpha=0.05$, SD: Standard deviation, CV: Coefficient of variation

Key: There is significance difference between $a^{*}$ and $b^{*}$

There is no significance difference between $\mathrm{a}^{*}$ and $\mathrm{c}^{*}$

There is significance difference between $\mathrm{S}^{*}$ and $\mathrm{D}^{*}$

Table 5. Support of some stakeholders for implementation of inclusive education

\begin{tabular}{|c|c|c|c|c|c|c|}
\hline \multirow{3}{*}{ Support from different stakeholders } & \multicolumn{6}{|c|}{ Respondents } \\
\hline & \multicolumn{2}{|c|}{$\begin{array}{l}\text { Teachers } \\
(N=78)\end{array}$} & \multicolumn{2}{|c|}{$\begin{array}{l}\text { Principals }(\mathrm{N}= \\
\text { 16) }\end{array}$} & \multicolumn{2}{|c|}{ Total $(\mathrm{N}=94)$} \\
\hline & No & $\%$ & № & $\%$ & № & $\%$ \\
\hline \multicolumn{7}{|l|}{ Special teachers } \\
\hline Not fair & 24 & 30.8 & 4 & 25 & 28 & 29.79 \\
\hline Fair & 10 & 12.8 & 3 & 18.8 & 13 & 13.83 \\
\hline Good & 20 & 25.6 & 6 & 37.5 & 26 & 27.66 \\
\hline Very good & 9 & 11.5 & 2 & 12.5 & 11 & 11.70 \\
\hline Excellent & 15 & 19.2 & 1 & 6.3 & 16 & 17.02 \\
\hline \multicolumn{7}{|l|}{ Sebeta teachers training colleges } \\
\hline Not fair & 19 & 24.4 & 4 & 25 & 23 & 24.47 \\
\hline Fair & 12 & 15.4 & 2 & 12.5 & 14 & 14.89 \\
\hline Good & 10 & 12.8 & 2 & 12.5 & 12 & 12.77 \\
\hline Very good & 25 & 32.1 & 5 & 31.3 & 30 & 31.91 \\
\hline
\end{tabular}




\begin{tabular}{lllllll}
\hline Excellent & 12 & 15.4 & 3 & 18.8 & 15 & 15.96 \\
Education office & & & & & & \\
$\quad$ Not fair & 32 & 41 & 7 & 43.8 & 39 & 41.49 \\
Fair & 12 & 15.4 & 1 & 6.3 & 13 & 13.83 \\
Good & 15 & 19.2 & 6 & 37.5 & 21 & 22.34 \\
Very good & 14 & 17.9 & 2 & 12.5 & 16 & 17.02 \\
Excellent & 5 & 6.4 & - & & 5 & 5.32 \\
\hline
\end{tabular}

However, 23 (24.47\%) of them were evaluated as not fair (see Table 5). Thus, supports given to primary schools teachers from various educational stakeholders to implement inclusive education were unsatisfactory.

\section{Discussion}

Inclusive education creates an opportunity for persons with disability to participate fully in all of the educational system. Implementation of the inclusive education depends to a large extent on the perceptions and ability of school principals and teachers to make accommodations for individuals with special needs [7]. Current study revealed, despite the fact that special needs education teachers plays critical role in implementation and experience sharing on knowledge and skills of inclusive education, there was limited number $3(3.19 \%)$ of teachers graduated with special needs education (SNE) in each school. On the other hand, experience sharing habit between present limited number of special needs education teachers and general teachers on inclusive education were not developed. As the result, their confidences to implement inclusion were varied. In contrary, other study revealed that the unity of teachers is very important for professional improvement and to enhance students' achievements' [13].

In present study, both school principals and teachers have positive attitudes towards implementation of inclusive education. However, there was significance difference between principals and teachers knowledge and perceptions on inclusive education $(\mathrm{p}<0.05)$. The knowledge and perceptions mean score of school principals $(27.93 \pm$ $2.1)$ is greater than that of teachers $(24.89 \pm 4.8)$ (see Table 2). These could be due more participation of schools principals than teachers on educational seminars at different levels. It is very important to fulfill inclusive materials besides training both principals and teachers on ways of implementing inclusive education. In line with the current study, the researchers' in Kenya analyzed Bahamas high school teachers' perceptions were revealed that teachers at the high school level demonstrated moderately positive attitudes toward inclusion [14]. Currently motivations of Dima guranda (knowledge mean score $=29.33$ ) and Mulugete Gadile (knowledge mean score $=26.60$ ) primary school teachers were very good to implement inclusive education. These could be due to the presence of special needs education resource room and trained man power on special needs education in both Dima guranda and Mulugeta Gadile primary schools. Most of teachers in these schools had got the chance to be trained on an inclusive education at different time. This could help them to develop positive attitudes towards implementing inclusive education and to be familiarized with different special needs educational materials (see Table 4).

In line with the current study, Hwang and Evans [15] were conducted research on thirty-three primary school teachers in Korea. The result showed general education teachers' had different motivations towards inclusion. Manisah et al [8] felt that the success of the inclusive education depends on the attitudes of classroom teachers towards the children with special needs.

In present study, teachers and school principals agreed on expected variables that could affect implementation of inclusive education. Supports given to primary schools teachers from various educational stakeholders to implement inclusive education were unsatisfactory. In line with this, Gaad and Khan [15] found that heavy teaching load in the mainstream classroom posed difficulties to meet the needs of students with special educational needs. In addition, Andrews and Frankel [5] recognized major factors that could affect the implementation of inclusive education were inadequate training, lack of skills to teach students with special needs, lack of appropriate infrastructure, and the nonexistence of adapted curricula in the classroom. Each of these factors affected the experiences of the teacher in the inclusive classroom and their attitude towards inclusive education. On the other hand, Gaad and Khan [16] confirmed that adequate teaching and learning materials, accessibility of a school environment is a resource that can enhance enrolment of special needs learners and a significant creation of inclusive settings. Korkmaz [13] affirms 
implementation of inclusive education appears to be successful when special needs education teachers' work collaboratively with general education teachers.

\section{Conclusion}

Both school principals and teachers had positive attitudes towards implementation of inclusive education. However, the actual implementation of inclusive education in general schools were not satisfactory. In appropriate class room setting, large number of students in the class, unsuitable school physical structures, lack of knowledge on inclusive education, lack of skills on implementation of inclusive education, lack of appropriate materials, lack of continuous training on inclusive education, and inappropriate curriculum towards disabled students are the main determinant factors that could affected teachers' motivations towards implementation of inclusive education. An experience sharing habit between special and general education teachers on knowledge and skills of inclusive education is very important for its actual implementation. Supports from different educational stakeholders are very crucial to implement inclusive education.

\section{Recommendations}

Teachers need to be trained about different disabilities. Hence, much effort is expected from educational stakeholders particularly Sebeta special needs education teachers College to empower teachers through providing continuous training. Class sizes would have to be reduced to allow the teacher sufficient time to accommodate all the students. School principals need to be proactive in ensuring inclusive education. They have to get specialized training to develop a sound understanding of what it means to implement an inclusive education in their schools. The active involvement and support of the schools' principals' in the implementation of inclusive education is critical. They have an essential role in improving the school environment and in implementing educational policy. Collaborative efforts between schools and various educational stakeholders to implement inclusive education are very important. Educational office needs to play great role in this respect through allocating budget to school improvement, teachers' capacity building, providing appropriate educational materials and society motivation to send child with special needs to schools.

\section{Acknowledgments}

I would like to express my earnest thanks to Sebeta Special Needs Education Teachers College for provision of stationary materials. I am profoundly grateful to Sebeta primary schools' principals and teachers for kind assistance they rendered me by providing valuable information towards inclusive education.

\section{References}

[1] Pfaffe J. Asefa E. Kedir N. and Teferra T. (2012). Comprehensive Evaluation of the General Education Quality Improvement Project: Final Baseline Report. Prepared for the MoE by Hifab International April 2012 Addis Ababa, Ethiopia.

[2] United Nations Educational, Scientific, and Cultural Organization (UNESCO) (2005). Ensuring accessto education for all; http://unesdoc.unesco.org/images/ 0014/001402/140224e.pdf (10 April, 2013)

[3] European Agency for Development in Special Needs Education (2012). The inclusive Education in action project; https://www.european-agency.org/Agencyprojects/ iea (23 May,2013).

[4] Ainscow, E., (2006). Improving Schools, DevelopingInlcusion. New york: Routledge.

[5] Andrews A. and Frankel E. (2010). Inclusive education in Guyana: A call for change. International Journal of Special Education, 25(1), 126-144.

[6] Buhere P, Judah N. and Jonah K. ( 2014). Inclusive Education and School Culture: Integration Issues for Mainstream Primary Schools in Kenya. International Journal of Education and Research,2(5),2201-6740

[7] Bender, W. N., Vail, C. O., \& Scott, K., (1995). Teacher attitudes toward increased mainstreaming: Implementing effective instruction for students with learning disabilities. Journal of LearningDisabilities, 28, 87-94.

[8] Manisah M., Ramlee M. and Zalizan M., (2006). An empirical study on teachers' perceptions: Towards inclusive education in malaysia. International journal of special education, 21(3), 36 - 44)

[9] MoE and UNICEF, (2012). Study on the situation of out of school Children (OOSC) in Ethiopia Report prepared for the MoE and UNICEF by ATEM Consultancy Addis Ababa, Ethiopia

[10] Creswell, J., (2003). Research Design: Qualitative, Quantitative, and Mixed Methods Approaches. London: Sage Publications. 
[11] Singh, Y. K., (2006). Fundamentals of research methodology and stastics. India (New Delhi): New Age international publishers.

[12] Gall,T., Gall, P., Borg, W., (2007).Educational research. An introduction (8th Ed.) Toronto, on: Ally \& Bacon.

[13] Korkmaz, I., (2011). Elementary Teachers perceptions about Implementation of Inclusive Education.US-China Education Reviews, 177-183.

[14] Janelle C., Yvonne H. and Norissa G., (2014). Breaking the Silence of Mainstream Teachers' Attituds towards Inclusive Education in the Bahamas: High School Teachers' Perceptions. TheQualitative Repot. 19 (84), 120.

[15] Hwang Y. and Evans, D., (2011). Attitudes towards inclusion: Gaps between beliefs and practice. International Journal of Special Education, 26(1), 136-146.

[16] Gaad E. \& Khan, L., (2007). Primary mainstream teachers' attitudes towards inclusion of Students with special education needs in the private sector: A perspective from Dubai. InternationalJournal of Special Education, 22(2), 95-109. 